\title{
Mechanical and Microstructural Properties of Friction Stir Welded Dissimilar Aluminum Alloys and Pure Copper Joints
}

\author{
W. Winarto ${ }^{1}, M$. Anis ${ }^{1}$, and B. Eka Febryansyah ${ }^{1}$ \\ ${ }^{1}$ Department of Metallurgy and Materials Engineering, Universitas Indonesia, Depok, Indonesia
}

\begin{abstract}
Joining dissimilar metal alloys such as aluminum and copper is very difficult to be done because of alterations in chemical, metallurgical and physical behavior. Friction Stir Welding (FSW) is a solid-state welding technique which is one of the new methods used for joining the dissimilar metal. The material used is aluminum alloy 5052 and pure copper plates. The welding parameters were carried out with variable geometry shape of pin tools: taper and threaded cylindrical pin tools. Also preheating were performed on the part of copper plates with temperatures at both $25^{\circ} \mathrm{C}$ and $200^{\circ} \mathrm{C}$. The friction stir welding of dissimilar joints was carried out at the rotary tool speed of $2800 \mathrm{rpm}$ with the angle of 1 degree and the welding travel speed of $2 \mathrm{~mm} / \mathrm{sec}$. All welds were then carried out to several mechanical testing and microscopic observation. The results show that the variable geometry shape of pin tools and pre-heating on the copper part affect the microstructure grain size and the formation of $\mathrm{Al}-\mathrm{Cu}$ inter-metallic phases. The creation of different structures influences the mechanical properties of the friction stir welds. The hardness of welds using threaded pin tools is higher than the tapper one. However, the tensile strength of dissimilar welds using the threaded cylindrical pin tools is lower than the tapper one. The fracture location commonly occurs at the part of aluminum plates having a brittle intermetallic phase.
\end{abstract}

\section{Introduction}

Joining dissimilar metal is unavoidable in fabricating and erecting modern engineering materials for machinery. Different types of metals used have different physical, chemical, and metallurgical properties. Hence, welding dissimilar metals are to combine different properties of metals provides reducing the costs of metals and simultaneously optimizing the performance of components. [1] Copper $(\mathrm{Cu})$ and aluminum $(\mathrm{Al})$ are two engineering materials commonly applied in electric power, transportation, and aerospace industries. The dissimilar joint of $\mathrm{Al} / \mathrm{Cu}$ is of great interest in electrical contacts because it can reduce the costs and weight as well as extending the service life [2].

Welding method was the main priority for manufacturing of dissimilar joint. However, arc fusion welding is not applicable for joining $\mathrm{Cu}$ to $\mathrm{Al}$ due to their alterations in chemical and metallurgical features [3]. Also, the dissimilar metal joining by fusion welding can produce the formation of crack and brittle intermetallic compounds (IMCs) which severely decreased the tensile properties of welds. Hence, many types of welding method such as FSW have developed a substitute welding process for joining $\mathrm{Al}$ to $\mathrm{Cu}$. [4]
Friction stir welding (FSW) was developed in 1991 by TWI in Britain and has been applied broadly in many industries nowadays [5]. There are commonly several regions of friction stir joints as explained by Threadgill [5] such as parent metal, the thermomechanical affected zone (TMAZ) and the heat-affected zone (HAZ) and the nugget of weld. Not only for joining, but friction stir technology has also been settled for processing metallic alloys to increase their significant properties [6]. This FSW method is very potential for the process of different materials and alloys [7].

Mukuna et al. [8] show that the friction stir welding technique provides more efficiency especially on joining the dissimilar $\mathrm{Al} / \mathrm{Cu}$. When the pin tools of FSW were improved, the welds can be produced at the high-quality [8]. However, in most of the study conducted on FSW between aluminum and copper, the design of tool shape is commonly not fully stated. The geometry of tools is a critical factor for creating the sound welds of dissimilar joints. 


\section{Experimental Method}

The FSW process used for joining between the aluminum alloy 5052 plates and the pure copper plates. The chemical compositions of both plates can be seen in Table 1 and Table 2 . The welding configuration used was a square butt joint of $50 \times 120 \times 6 \mathrm{~mm}^{3}$. The FSW parameters used for producing dissimilar joints were shown in Table 3. All the other settings were kept constant. The pin tools used are made of high-speed steel (HSS) type with a cylindrical shape and a threaded cylindrical taper, as shown in Figure 1. The pre-heating is on the part of the copper side by using the gas burner. Heating is carried out at temperatures up to $200{ }^{\circ} \mathrm{C}$.

Table 1. The elemental composition of AA5052 (wt. \%)

\begin{tabular}{|c|c|c|c|c|c|c|c|}
\hline $\mathrm{Al}$ & $\mathrm{Fe}$ & $\mathrm{Si}$ & $\mathrm{Zn}$ & $\mathrm{Mg}$ & $\mathrm{Mn}$ & $\mathrm{Cu}$ & Others \\
\hline 97.7 & 0.4 & 0.25 & 0.1 & 0.15 & 0.1 & 0.1 & 0.15 \\
\hline
\end{tabular}

Table 2. The elemental composition of pure $\mathrm{Cu}$ (wt. \%)

\begin{tabular}{|c|c|c|c|c|c|c|c|c|}
\hline $\mathrm{Cu}$ & $\mathrm{Fe}$ & $\mathrm{Pb}$ & $\mathrm{Zn}$ & $\mathrm{P}$ & $\mathrm{Si}$ & $\mathrm{Mg}$ & $\mathrm{Mn}$ & $\mathrm{Al}$ \\
\hline 99.95 & 0.01 & 0.00 & 0.001 & 0.014 & 0.00 & 0.00 & 0.00 & 0.00 \\
\hline
\end{tabular}

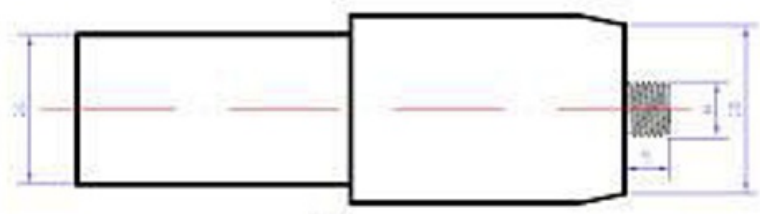

(a)

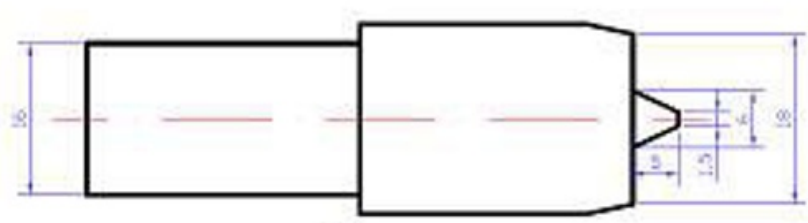

(b)

Fig 1. Tools geometry with (a) Threaded. (b) Tapered cylindrical

The welds joint was manufactured using a milling machine as seen in Figure 2. The weld specimens were prepared for metallography analysis for the various location of the weld joint by using an optical microscope. The metallograph observation was used for analyzing the microstructure and the feature of material flow on the dissimilar joints. The polished mirror specimens were prepared by using a Keller's reagent to observe the microstructural welds. The inter-metallic compounds were analyzed using scanning electron microscope (SEM), and microchemical was determined by using EDS to evaluate the thickness, size, and distribution of it.
Table 3. Friction stir welding parameters

\begin{tabular}{|c|c|c|}
\hline Type of Pin Tools & Parameters & Units \\
\hline \multirow{2}{*}{ Taper Cylindrical } & Rotational speed & $2800 \mathrm{rpm}$ \\
\cline { 2 - 3 } & \multirow{2}{*}{ Thilting angle } & $1 \mathrm{deg}$ \\
\cline { 2 - 3 } Threaded Cylindrical & Welding speed & $2 \mathrm{~mm} / \mathrm{sec}$ \\
\hline
\end{tabular}
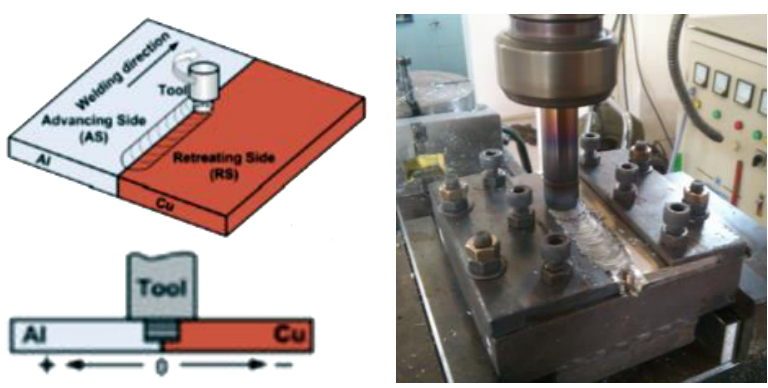

Fig 2. The dissimilar FSW process
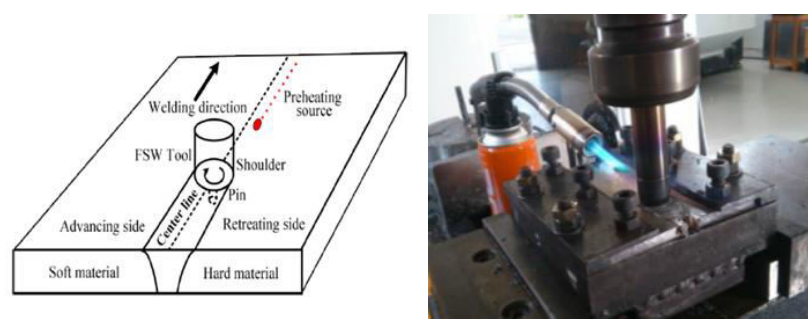

Fig 3. Dissimilar FSW process with pre-heating

Mechanical properties are examined using a micro Vickers hardness test and tensile strength test. Micro Vickers test performed on a 7-point weld area with a load of $300 \mathrm{kgf}$ for 10 seconds. The tensile test samples are prepared by using ASTM standard E8M-04 and carried out at a speed of $1 \mathrm{~mm} / \mathrm{sec}$.

\section{Results and Discussion}

\section{3 .1. Metallographic Structures of FSW Weld}

The effect of dissimilar FSW $\mathrm{Al}$ and $\mathrm{Cu}$ and macrostructure is shown in Figure 4. The surface appearance on welds without preheating seems to be rough on weld bead surface compared to the preheating one. Welds using threaded cylindrical pin tools have more significant stirring zone structure (black color) than the weld using tapper cylindrical pin tools. It is due to the mixture of $\mathrm{Al}-\mathrm{Cu}$ metals increased with using the threaded cylindrical pin tools. 
(a)

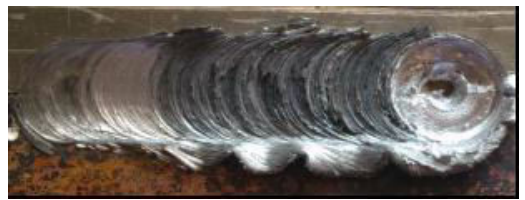

(b)

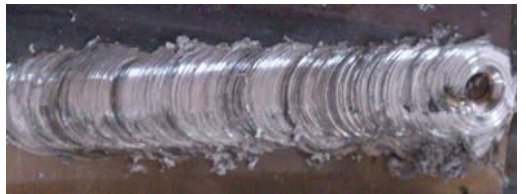

(c)

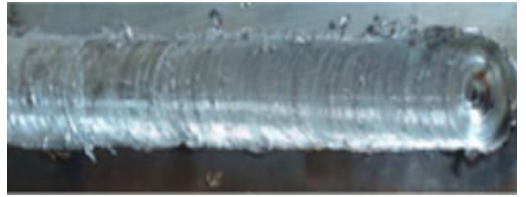

(d)

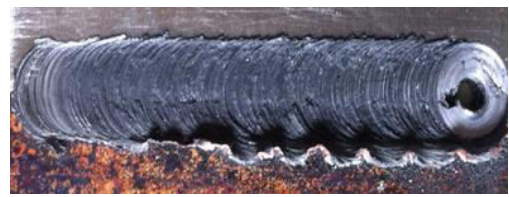

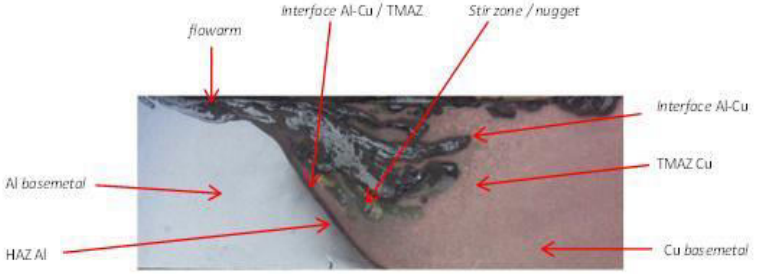
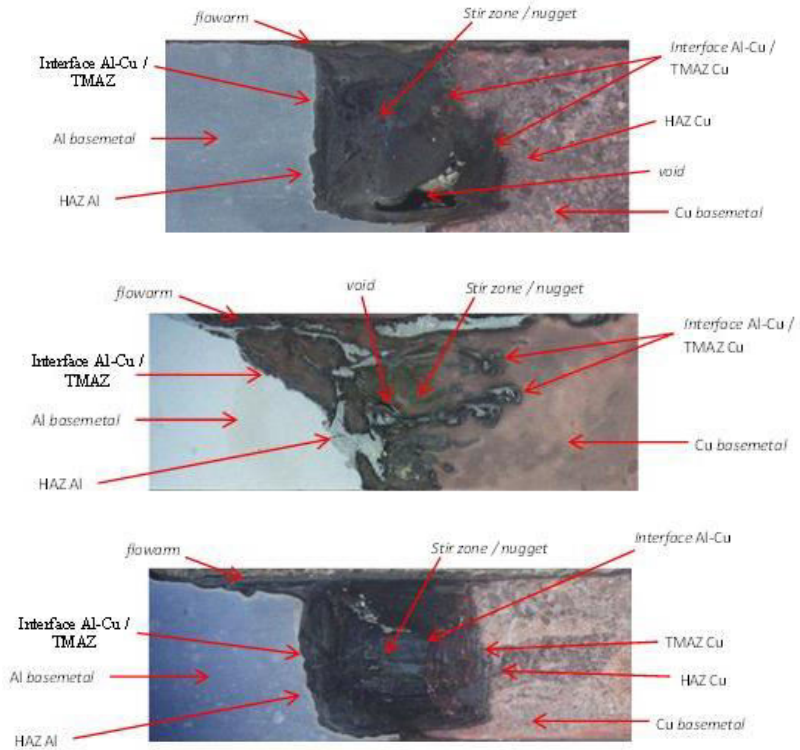

Fig 4. The macro-structure of Al - Cu disimilar FSW with pin tools of: (a) taper cylindrical (b) threaded cylindrical (c) taper cylindrical with pre-heating (d) threaded cylindrical with pre-heating

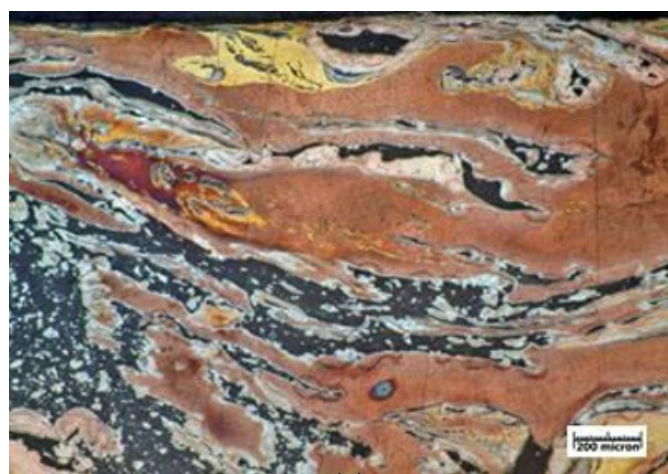

(a)

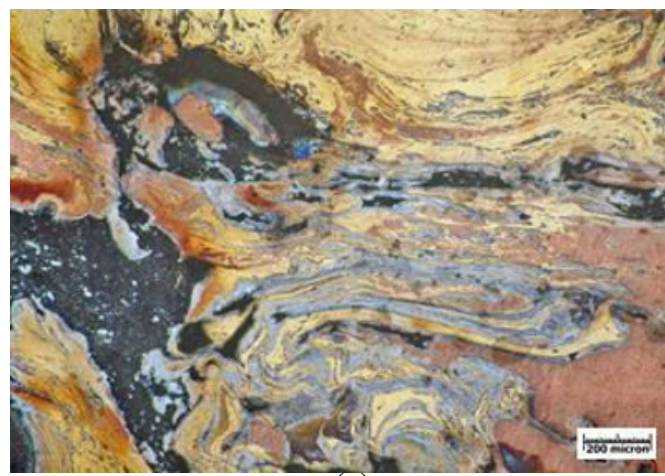

(c)

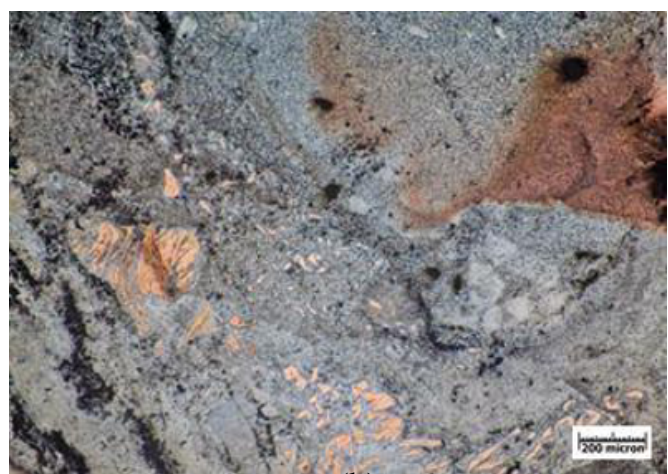

(b)

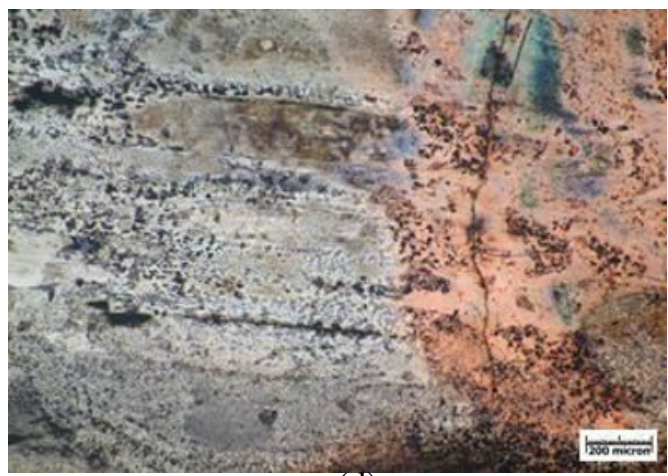

(d)

Fig 5. Microstructure of stir weld zone with the pin tools of: (a) taper cylindrical; (b) threaded cylindrical; (c) taper cylindrical with pre-heating; (d) threaded cylindrical with pre-heating 
Using the higher magnification of the microscope as seen in Figure 5, it shows that the part stir zone/nugget zone between $\mathrm{Al}$ and $\mathrm{Cu}$ are shown. The observation of an optical microscope showing the microstructure of $\mathrm{Al}-\mathrm{Cu}$ mixed phase has a somewhat yellowish color, in contrast with the color of the base metal of $\mathrm{Cu}$ and $\mathrm{Al}$. According to Liu et al. [9], the boundary between copper and aluminum was ostensible, and a plastic combination of materials at the border occurred. The formation of good material flow indicated by a circular ring occurred between the copper and aluminum interface.

The microstructure on the weld interface between aluminum and copper was taken by scanning electron microscope (SEM) and included the chemical composition test by using Energy Dispersive Spectrometry (EDS) as can be seen from Figure 6 to Figure 9. The thin layer of the interface is formed in the FSW dissimilar joint of Al-Cu. The average thickness is the range of 5-10 $\mu \mathrm{m}$ on the section between $\mathrm{Al}$ and regional base metal stir zone. This thin layer contained the compound around large copper particles and small copper particles, and it is called intermetallic compounds (IMCs). The results of chemical composition test by using EDS showed that the chemical composition is almost balanced between $\mathrm{Al}$ and $\mathrm{Cu}$, so that suggests the formation of intermetallic phases formed between aluminum and copper at temperatures approaching the melting of IMCs.
According to Xue at al [10], aluminum reacted with copper creating some compounds near large copper particles and small copper particles. Hence copper gets converted into the intermetallic compound.

There are found a crack in the Al-Cu interface of dissimilar weld especially at the TMZ Aluminum as seen in Figure 6 and Figure 7. Also, there are also found the weld defects in the form of voids (porosity). This void appears in the weld using the threaded cylindrical pin tools as seen in Figure 7 and Figure 9. According to Bisadi et al., some weld defects were a presence when welding was performed at a low temperature. However, when welding was carried out at a very high temperature, some voids (cavities) were formed at the interface [11]. Also, Xue et al. found that in the weld interface had a good metallurgical bonding observed in the dissimilar Al-Cu welds joined by FSW [12].

The results of chemical composition test by using EDS showed that the chemical composition is almost balanced between $\mathrm{Al}$ and $\mathrm{Cu}$, so that suggests the formation of intermetallic phases formed between $\mathrm{Al}$ and $\mathrm{Cu}$ at temperatures approaching the melting.
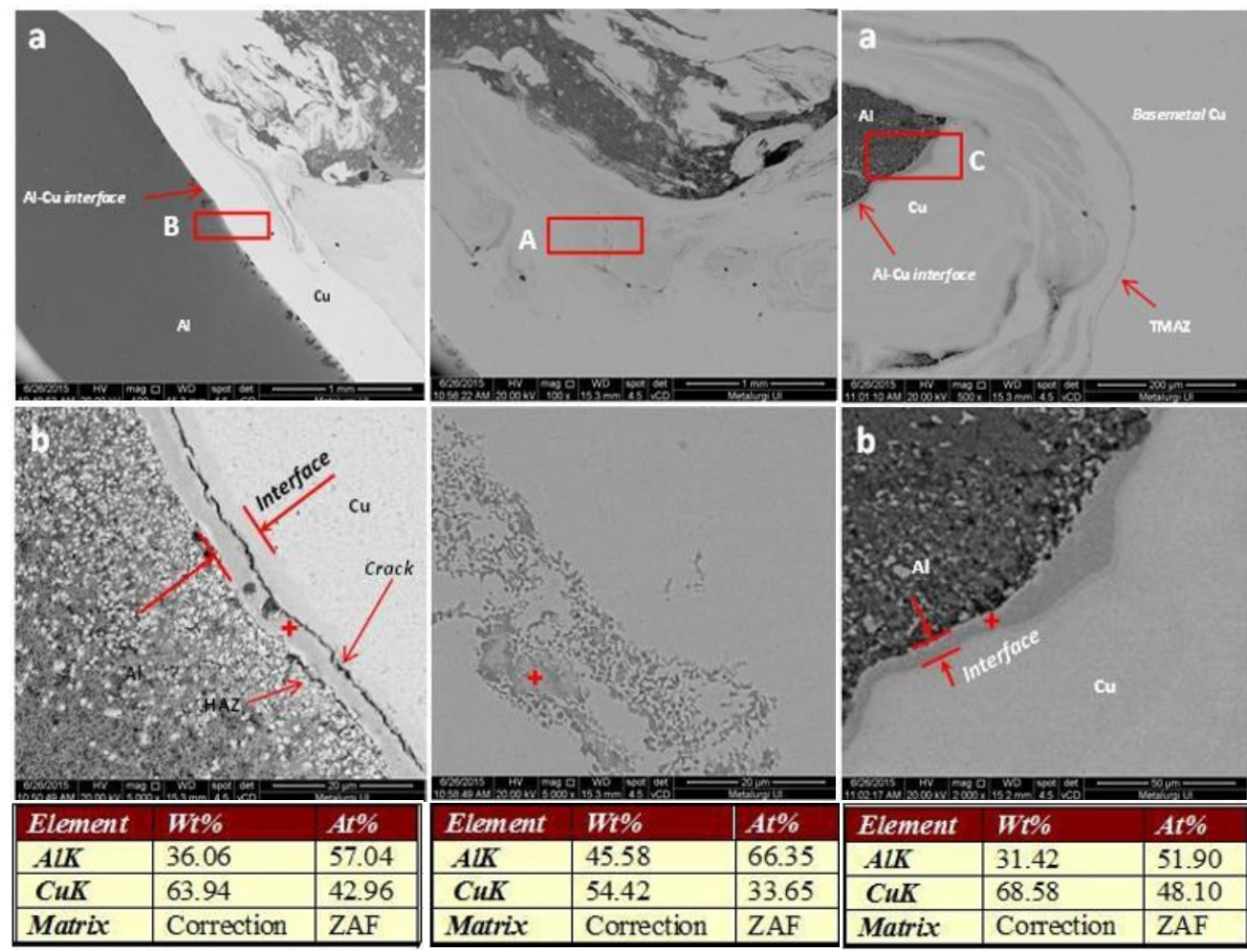

Fig 6. Microstructure disimilar FSW pin tools taper cylindrical and no-preheat observed by SEM-EDS; (1) interface/TMAZ Al (2) stir zone/nugget (3) interface/TMAZ Cu 
1

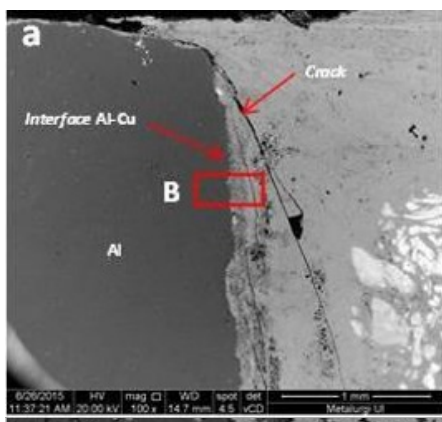

b

HAz
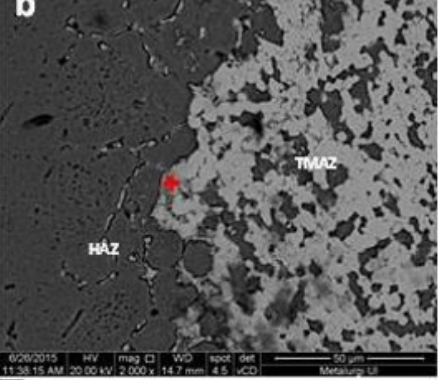

2

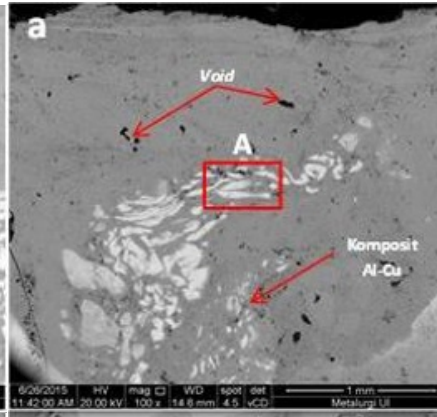

b

\begin{tabular}{|l|l|l|}
\hline AlK & 62.91 & 79.98 \\
\hline CuK & 37.09 & 20.02 \\
\hline Matrix & Correction & ZAF \\
\hline
\end{tabular}

\begin{tabular}{||l|l|l|}
\hline Element & $\boldsymbol{W t} \%$ & At $\%$ \\
\hline AlK & 46.43 & 67.12 \\
\hline CuK & 53.57 & 32.88 \\
\hline Matrix & Correction & ZAF \\
\hline
\end{tabular}

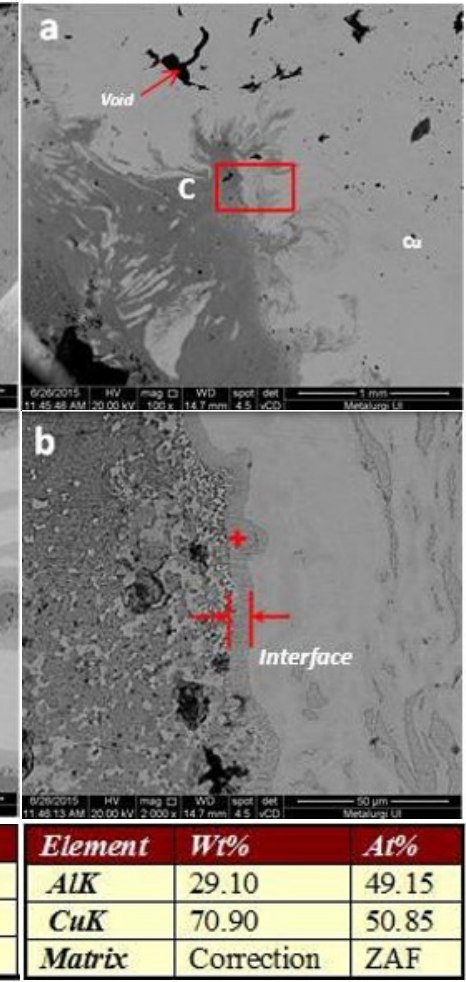

Fig 7. Microstructure disimilar FSW pin tools taper cylindrical and no-preheat observed by SEM-EDS; (1) interface/TMAZ Al (2) stir zone/nugget (3) interface/TMAZ Cu

1
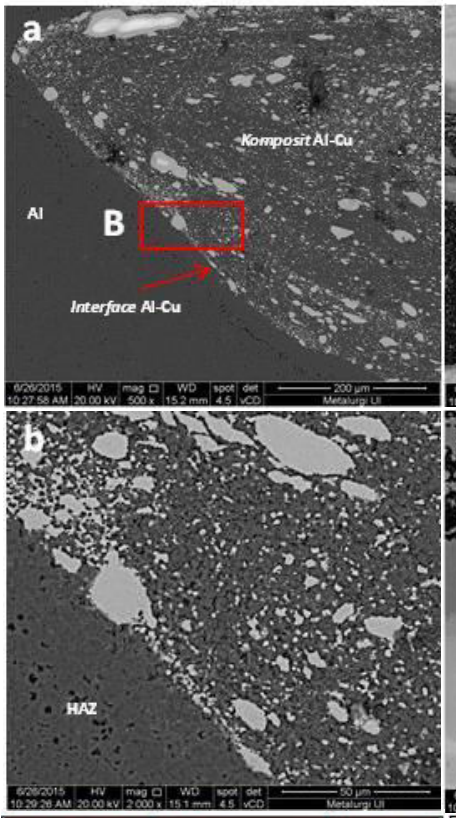

\begin{tabular}{|l|l|l|}
\hline Element & Wt\% & At\% \\
\hline AlK & 60.30 & 78.15 \\
\hline CuK & 39.70 & 21.85 \\
\hline Matrix & Correction & ZAF \\
\hline
\end{tabular}

2

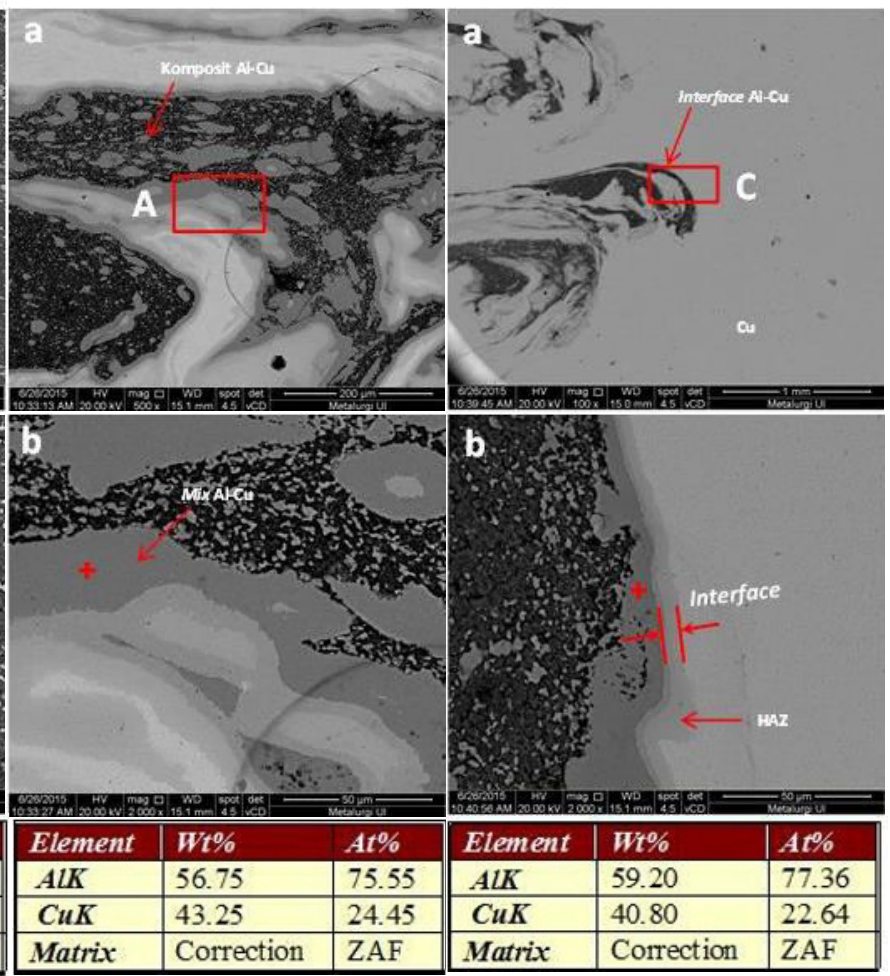

Fig 8. Microstructure dissimilar FSW pin tools threaded cylindrical with pre-heating observed by SEM-EDS; (1) interface/TMAZ Al (2) stir zone/nugget (3) interface/TMAZ Cu 
1

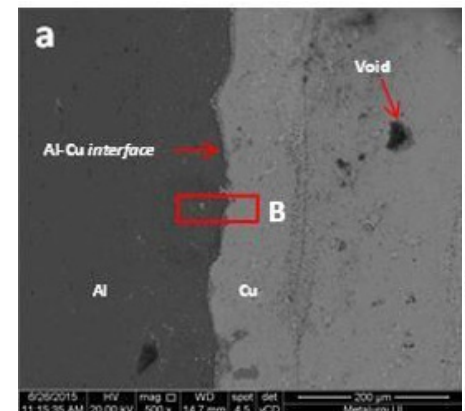

b

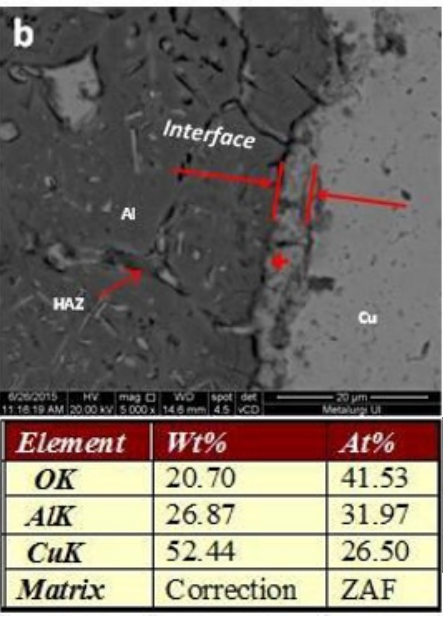

2

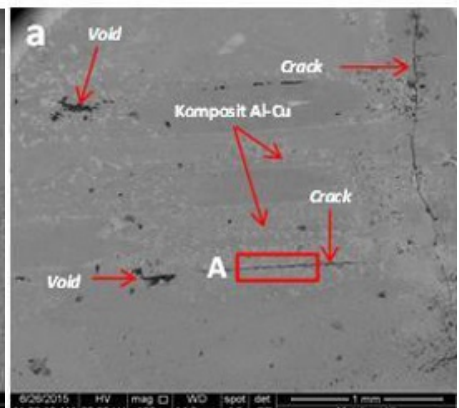

b

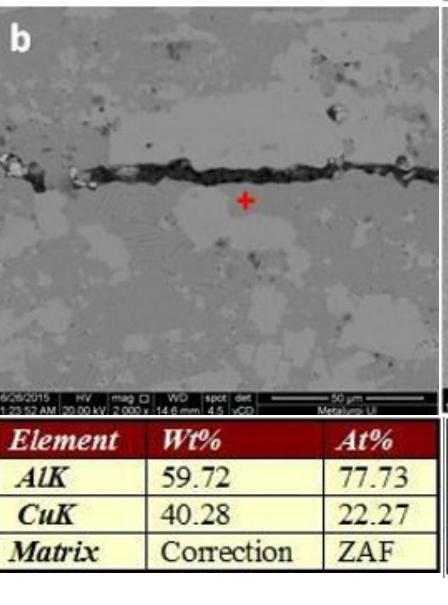

3
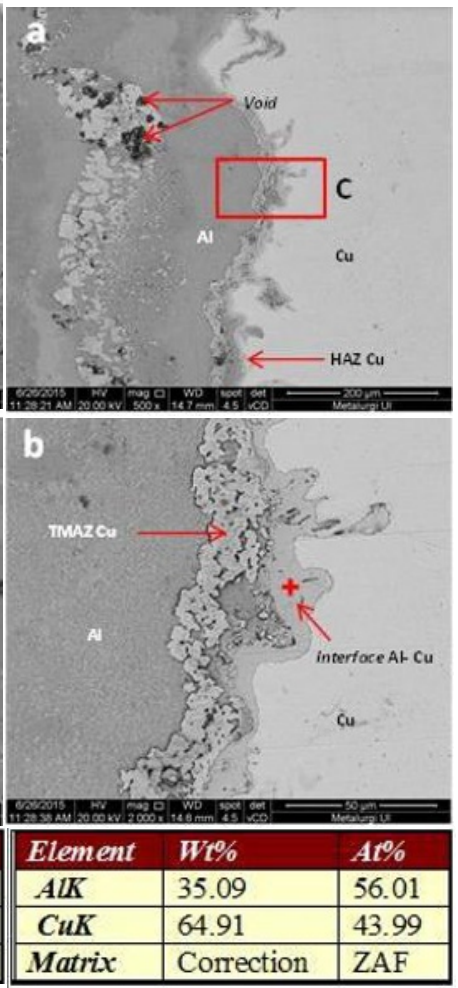

Fig 9. Microstructure dissimilar FSW pin tools threaded cylindrical with pre-heating observed by SEM-EDS; (1) interface/TMAZ Al (2) stir zone/nugget (3) interface/TMAZ Cu

\subsection{Mechanical Properties of FSW Welds}

The indented location of micro-hardness Vickers on the weld specimen can be seen in Fig. 10. The result of the hardness test can be shown in Fig. 11, then the result of the tensile test can be seen in Fig. 12. The location of the fracture after the tension testing can be seen in Table 4 .

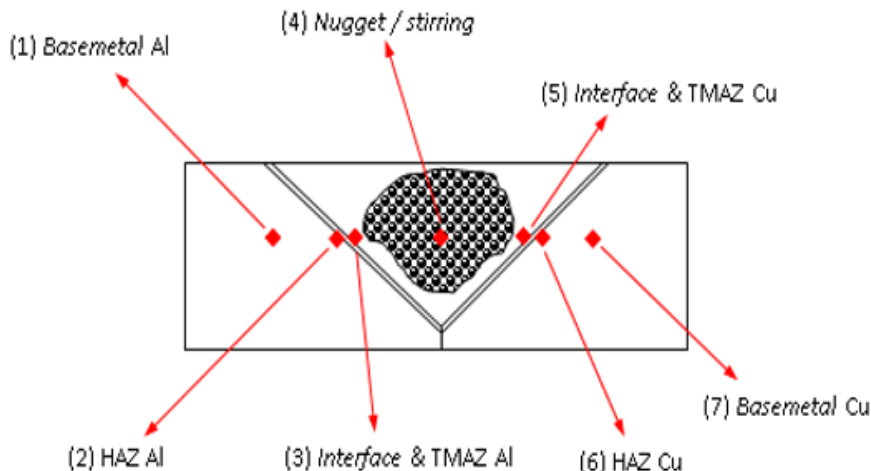

Fig 10. Indentation mapping of micro Vickers hardness test on FSW weld samples
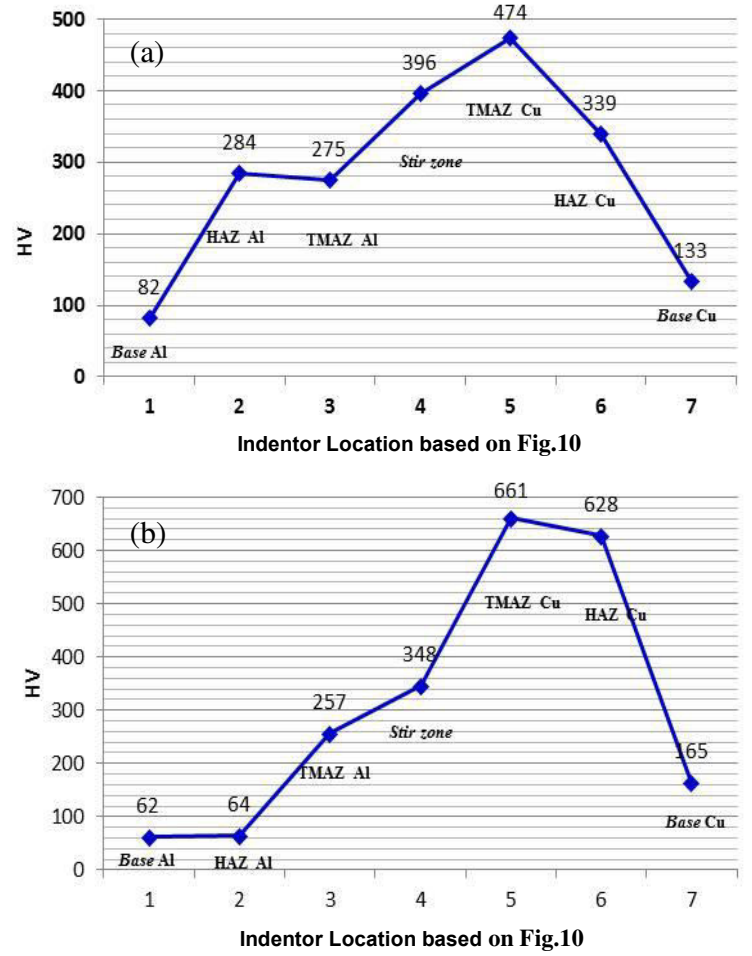

Fig 11. Micro-hardness distribution test on welds with no preheat using the pin tool of (a) taper (b) threaded 

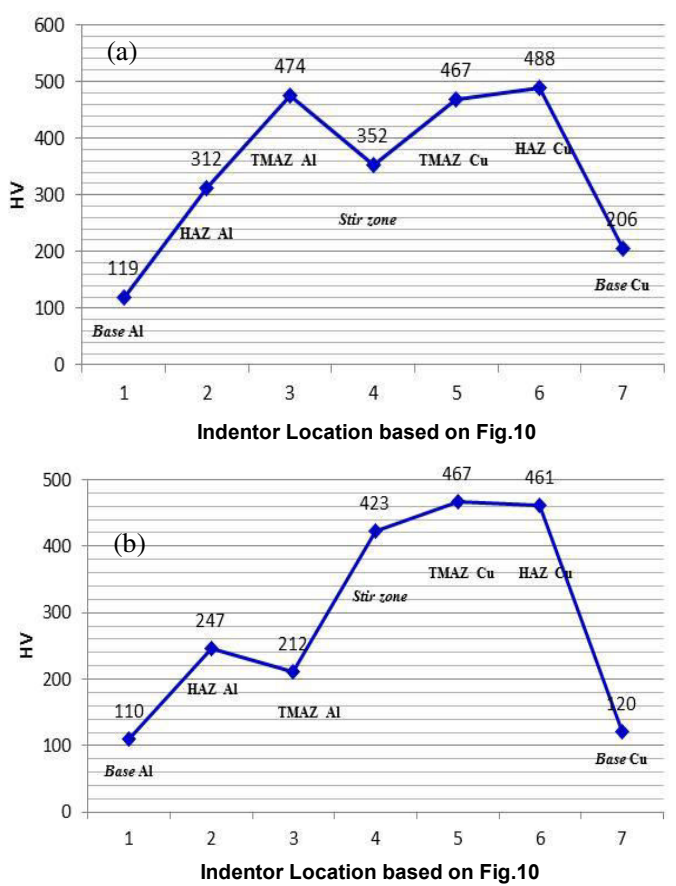

Fig 12. Micro-hardness distribution test on welds with preheat using the pin tool of (a) taper (b) threaded

Hardness test results in Fig. 11 shows that an increase in mechanical properties such as hardness in the weld area when compared with both base metal $\mathrm{Al}$ and $\mathrm{Cu}$. An increase in the average hardness value of about $60 \%$. Factors Increasing the hardness value is influenced by the stirring process that causes the phase of $\mathrm{Al}$ and $\mathrm{Cu}$ split into fine grains and mixed that is spread on the weld area as composite particles of $\mathrm{Al}-\mathrm{Cu}$ and $\mathrm{Al}-\mathrm{Cu}$ intermetallic phase. At welding with pre-heating area base metal, HAZ, and TMAZ hardness value is much higher than in welding without pre-heating, the part most likely exposed to the effects of pre-heating process is performed on $\mathrm{Cu}$ so that the properties of hardness increases.

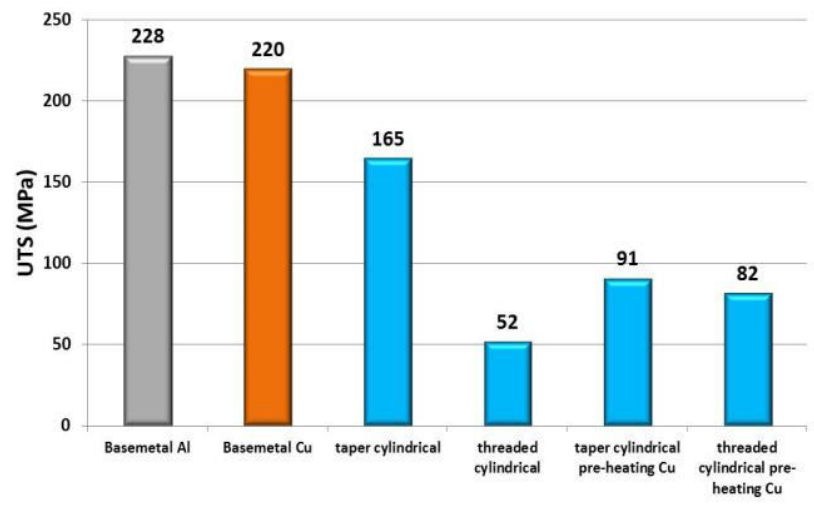

Fig 13. The tensile strength of the base metal \& the dissimilar welds and compared with parameters
The results of the tensile test on FSW dissimilar weld joints as seen in Figure 13 showed that the FSW weld produced by using taper cylindrical pin tools have the higher tensile strength of $165 \mathrm{MPa}$ compared with the welds using threaded cylindrical pin tools of $52 \mathrm{MPa}$ without any preheating. The low UTS on the threaded cylindrical pin tools is due to the presence of weld defects such as cracks and void (porosity) with considerable amounts in the weld stirring zone. According to Akinlabi et al. [13], the increasing weld microhardness value at the interface because of the presence of strain hardening.

Table 4. The tensile strength of dissimilar welds and fracture

\begin{tabular}{|c|c|c|c|}
\hline FSW variable & $\begin{array}{c}\text { UTS } \\
\text { (MPa) }\end{array}$ & $\begin{array}{c}\text { Fracture } \\
\text { Location }\end{array}$ & $\begin{array}{c}\text { Picture of } \\
\text { The fracture area }\end{array}$ \\
\hline $\begin{array}{c}\text { Pin tools taper } \\
\text { cylindrical }\end{array}$ & 165 & $\mathrm{HAZ} \mathrm{Al}$ & \\
\hline $\begin{array}{c}\text { Pin tools threaded } \\
\text { cylindrical }\end{array}$ & 52 & $\mathrm{HAZ} \mathrm{Al}$ \\
\hline $\begin{array}{c}\text { Pin tools taper } \\
\text { cylindrical pre- } \\
\text { heating }\end{array}$ & 91 & $\begin{array}{c}\text { Nugget/ stir } \\
\text { zone }\end{array}$ \\
\hline $\begin{array}{c}\text { Pin tools threaded } \\
\text { cylindrical pre- } \\
\text { heating }\end{array}$ & 82 & $\mathrm{HAZ} \mathrm{Al}$ & \\
\hline
\end{tabular}

The effect of preheating on the mechanical properties of dissimilar weld joints as seen in Figure 13 showed that the ultimate tensile test of welds decreased when the preheating applied during welding. It is because the effect of pre-heating process on $\mathrm{Cu}$ base metal may cause extremely high temperatures which would then affect the aluminum which tends to form brittle structures at the HAZ Aluminum. According to several researchers [1419], it shows that the dramatic changes in the mechanical properties of the weld joint because of the inter-metallic layer at the interface and the formation of cavities (void)

\section{Conclusion}

The variable geometry shape of pin tools and pre-heating on the copper part affect the microstructure grain size and the formation of $\mathrm{Al}-\mathrm{Cu}$ inter-metallic phases. The use of tapper cylindrical pin tools produces an excellent weld structure with few weld defects and hence have good mechanical properties for FSW dissimilar $\mathrm{Al}-\mathrm{Cu}$ joints. The hardness of welds is mostly higher in the area of the weldment. The tensile strength of dissimilar welds using the taper cylindrical pin tools is higher than the threaded cylindrical one. The effect of the pre-heating process on $\mathrm{Cu}$ base metal may cause extremely high temperatures which would then affect the aluminum to form brittle structures at the HAZ Aluminum. Therefore, the fracture location of a tensile test commonly occurs at the part of aluminum plates having a brittle intermetallic phase. 
We would like to express our gratitude for the support of research funding from the Directorate of Research and Community Service of Universitas Indonesia through the PITTA Program 2018 with the Contract No. 2558/UN2.R3.1/HKP.05.00/2018

\section{References}

1. Simoncini M, Forcellese A. Effect of the welding parameters and tool configuration on micro- and macro-mechanical properties of similar and dissimilar FSW joints in AA5754 and AZ31 thin sheets. Mater Des (2012); 41:50-60.

2. Honarpisheh M, Asemabadi M, Sedighi M. Investigation of annealing treatment on the interfacial properties of explosive-welded $\mathrm{Al} / \mathrm{Cu} / \mathrm{Al}$ multilayer. Mater Des (2012); 37:122-7.

3. Mai TA, Spowage AC. Characterization of dissimilar joints in laser welding of steel-Kovar, copper-steel, and copper-aluminum. Mater Sci Eng. A (2004); 374:224-33.

4. Sheng LY, Yang F, Xi TF, Lai C, Ye HQ. Influence of heat treatment on the interface of $\mathrm{Cu} / \mathrm{Al}$ bimetal composite fabricated by cold rolling. Composites: Part B (2011); 42:1468-73.

5. P.L. Threadgill, A.J. Leonard, H.R. Shercliff, P.J. Withers, Friction stir welding of aluminum alloys, International Materials Reviews 54 (2009) 49-93.

6. Z.Y. Ma, Friction stir processing technology: a review, Metallurgical, and Materials Transactions A 39 (2008) 642-658.

7. A.G. Rao, B.R.K. Rao, V.P. Deshmukh, A.K. Shah, B.P. Kashyap. (2009). Microstructural refinement of a cast hypereutectic Al-30Si alloy by friction stir processing. Elsevier: Materials Letters 63 (2009) 2628-2630.

8. Mukuna P. Mubiayi, Ester T. Akinlabi, "Friction Stir Welding of Dissimilar Materials between Aluminum Alloys and Copper- An Overview," Proceedings of the World Congress on Engineering 2013, Vol. III, WCE 2013, July 3 - 5, (2013), ISSN: 2078-0958, London, U.K.

9. Peng Liu, Qingyu Shi, Wei Wang, Xin Wang, Zenglei Zhang, "Microstructure and XRD analysis of FSW joints for copper T2/aluminum 5A06 dissimilar materials", Materials Letters, 62, (2008), pp 4106-4108.

10. P. Xue, B.L. Xiao, D.R. Ni, Z.Y. Ma, "Enhanced mechanical properties of friction stir welded dissimilar Al-Cu joint by intermetallic compounds," Materials Science and Engineering A, (2010) 527, pp 5723-5727.

11. H. Bisadi, A. Tavakoli, M. Tour Sangsaraki, K. Tour Sangsaraki, "The influences of rotational and the influences of rotational and welding speeds on microstructures and mechanical properties of friction stir welded Al5083, and commercially pure copper sheets lap joints", Materials and Design, 43, (2013), pp 80-88.

12. P. Xue, B. L. Xiao, D. Wang, And Z. Y. Ma, "Achieving high property friction stir welded aluminum/copper lap joint at low heat input," Science and Technology of Welding and Joining,16, No 8, (2011) pp.657-661.

13. Esther T. Akinlabi, Randall D. Reddy, Stephen A. Akinlabi, "Microstructural Characterizations of Dissimilar Friction Stir Welds" Proceedings of the World Congress on Engineering (WCE), 2012, III, pp. 4 - 6

14. A. Esmaeili, M. K. BesharatiGivi, H. R. Zareie Rajani, "A metallurgical and mechanical study on dissimilar Friction Stir welding of aluminum 1050 to brass (CuZn30)" Materials Science and Engineering, (2011), A 528, pp. 7093-7102.

15. P. Xue. B.L, Xiao. D.R, Ni, Z.Y, Ma., Enhanced mechanical properties of friction stir welded dissimilar $\mathrm{Al}-\mathrm{Cu}$ joint by intermetallic compounds. Elsevier: Materials Science and Engineering A 527 (2010) 5723-5727

16. C.W, Tan. Z.G. L. Q, Jiang. Li, Y.B. Chen, X.Y. Microstructural evolution and mechanical properties of dissimilar Al-Cu joints produced by friction stir welding. Elsevier: Materials and Design 51 (2013) 466-473

17. Moshwan, Raza. Yusuf, Farazila Yusof. Hasan, M. A. Hassan. Rahmat, S. M. (2014). Effect of tool rotational speed on force generation, microstructure and mechanical properties of friction stir welded Al$\mathrm{Mg}-\mathrm{Cr}-\mathrm{Mn}$ (AA 5052-O) alloy. Elsevier: Materials and Design 66 (2015) 118-128

18. Aval, Hamed Jamshidi. (2014). Influences of pin profile on the mechanical and microstructural behaviors in dissimilar friction stir welded AA6082AA7075 butt Joint. Elsevier: Materials and Design 67 (2015) 413-421

19. I. Galvão, D. Verdera, D. Gesto, A. Loureiro, D.M. Rodrigues. (2013). Influence of aluminum alloy type on dissimilar friction stir lap welding of aluminum to copper. Elsevier: Journal of Materials Processing Technology 213 (2013) 1920- 1928. 